IN MEMORIAM

\title{
DR. ELLIOT GOLDNER
}

\author{
By Louise Bradley
}

In December, 2016, Canada's mental health community lost a renowned psychiatrist, an esteemed researcher, and a pioneer who helped translate scientific findings into concrete health policy.

Dr. Elliot Goldner, a dear friend to the Mental Health Commission of Canada, and renowned as an intellectual giant in our community, passed away suddenly. At the age of 63, Dr. Goldner was in his prime, having accrued a lifetime of invaluable knowledge, and he had skillfully honed the ability to share it.

Universally respected for his unique combination of warmth, scientific rigour, and drive to create a mental healthcare system that put people's needs at its core, Dr. Goldner's early experiences as the father of an ill child informed his compassionate, people-centred approach.

As wise as he was generous, Dr. Goldner's approachable and informative writing style were showcased in his many works, including A Concise Introduction to Mental Health in Canada, a veritable treasure trove of information, each page stamped with his wisdom, compassion, and desire for transformational change.

Among the MHCC's most trusted advisers, Dr. Goldner shaped the organization's world renowned Knowledge Exchange Centre (KEC) with a keen eye to sharing best practises and speeding the transition of research into policy. Most recently, Dr. Goldner championed the development of Canada's first set of mental health indicators.

A recipient of the Alex Leighton award, bestowed jointly by the Canadian Psychiatric Association and the Canadian Academy of Psychiatric Epidemiology (CAPE) on individuals who have contributed to the advancement of psychiatric epidemiology, Dr. Goldner embodied the spirit of innovation and knowledge transfer, which the award is intended to recognize.

While many of us continue to mourn the loss of a dear friend, we may take a measure of comfort in knowing that Dr. Goldner leaves behind a legacy of young scientists inspired to apply their work to policy development. An academic and an intellectual with a common touch, Dr. Goldner's special gift was making regular people understand complex things.

He is dearly missed. 